\title{
DIREITOS HUMANOS E GOVERNANÇA GLOBAL: A AÇÃO DA CÁTEDRA SÉRGIO VIEIRA DE MELLO NA INTEGRAÇÃO LOCAL DOS REFUGIADOS.
}

\author{
HUMAN RIGHTS AND GLOBAL GOVERNANCE: THE SERGIO VIEIRA DE \\ MELLO ACADEMIC CHAIR INITIATIVE ON THE LOCAL INTEGRATION OF \\ REFUGEES.
}

\author{
${ }^{1}$ Camila Marques Gilberto \\ ${ }^{2}$ Fernanda De Magalhães Dias Frinhani
}

\begin{abstract}
RESUMO
O presente trabalho tem por objetivo analisar a relação da governança global com a proteção aos direitos humanos e aos direitos dos refugiados, em um cenário de aumento do fluxo global de migrantes forçados. Foi realizada pesquisa bibliográfica, utilizando-se as Cátedras Sérgio Vieira de Mello como exemplo de boas ações de governança. Concluiu-se que a responsabilidade compartilhada e a participação ampliada se mostram fundamentais para a efetividade das políticas públicas de proteção e integração dos refugiados, sendo a academia um importante espaço para produção de conhecimento, divulgação de saberes, informação e inclusão do refugiado na comunidade local.
\end{abstract}

Palavras-chave: Refugiados, Governança global, Cátedra sérgio vieira de mello, Integração local

\begin{abstract}
This article examines the relationship between global governance and the protection of human rights and the rights of refugees, in a scenario of increased global flow of forced migration. The study was based on bibliographic research, focusing on the Sergio Vieira de Mello Academic Chairs as an example of good governance actions. It was concluded that the shared responsibility and expanded participation are fundamental to the effectiveness of public policies for the protection and integration of refugees, being the academy an important space for knowledge production, dissemination of knowledge, information and inclusion of refugees in the local community.
\end{abstract}

Keywords: Refugees, Global governance, Sergio vieira de mello academic chair, Local integration

\footnotetext{
${ }^{1}$ Mestre em Direito pela University College of London - UCL, Londres, (Inglaterra). Professora do Curso de Graduação em Direito pela Universidade de Ribeirão Preto - Unaerp, Campus Guarujá. E-mail: tutortreinamento@gmail.com (Brasil)

${ }^{2}$ Doutora pela Faculdade de Direito da Universidade de São Paulo - USP, (Brasil). Docente da Graduação em Direito e em Relações Internacionais e do Programa de Pós-Graduação Stricto Sensu em Direito da Universidade Católica de Santos, São Paulo. E-mail: tutortreinamento@gmail.com
} 


\section{INTRODUÇÃO}

O presente trabalho tem por objetivo analisar a relação da governança global com a proteção aos direitos humanos e aos direitos dos refugiados, com foco no atual contexto imigratório brasileiro. O deslocamento forçado ocasionado por temor de perseguição ou em razão de catástrofes ambientais ou humanitárias tem levado ao aumento do fluxo migratório para o Brasil, sendo fundamental a análise, nesta perspectiva de deslocamentos forçados, de um dos elementos que compõem a governança global, a participação ampliada.

Sendo a governança reconhecidamente uma importante ferramenta na solução de problemas comuns, discute-se a efetividade de um de seus elementos intrínsecos, a participação ampliada representada, também, pela sociedade civil, no cenário de proteção, promoção e efetivação de direitos, na perspectiva do sistema internacional de proteção à pessoa humana.

Metodologicamente a pesquisa foi desenvolvida com base em pesquisa bibliográfica, com foco em estudos sobre governança global, apontando seus conceitos, enfocando a cooperação internacional propiciada pela multiplicidade de atores envolvidos na busca de soluções a problemas ou inquietudes mundiais. Foi discutida a relação da governança global com a proteção de direitos humanos, sendo dada ênfase à proteção dos direitos humanos na perspectiva da proteção dos direitos dos refugiados, considerando a necessidade e possibilidade de articulação entre atores estatais e não estatais.

A participação das Cátedras Sérgio Vieira de Mello no comprometimento com a proteção dos refugiados foi utilizada como exemplo de boas ações de governança apontando que a participação ampliada é bem vinda e que um sistema de governança é aquele que canaliza ou altera determinados comportamentos para, através do consenso, eliminar ou aliviar substancialmente o problema que levou a sua criação.

\section{GOVERNANÇA GLOBAL E PARTICIPAÇÃO AMPLIADA}

Muito se discute sobre a viabilidade de um Estado unitário, centralizado ou federalista, para dar corpo a um governo global. Somente assim seria possível lidar de forma eficaz com os problemas práticos como a proteção aos direitos humanos em geral e, especificamente, a crise humanitária vivida pelos refugiados, que tanta inquietude causam na sociedade global.

Críticos desta linha de raciocínio temem que a criação de um governo global poderia ameaçar a liberdade e soberania dos Estados, enquanto uma estrutura dividida em unidades 
menores seria capaz de melhor representar os diversos interesses globais e proporcionar maior fiscalização sobre abusos de poder (WAPNER, 1997).

Neste cenário surgem alternativas mais concretas que poderiam contemplar os mais diversos interesses, como é o caso da governança global.

O termo "governança global", surgido na década de 1980, estava inicialmente relacionado à atuação das Organizações Internacionais - como o Banco Mundial - no estabelecimento de padrões de "boa governança" junto à países subdesenvolvidos na definição de financiamentos e ajuda internacional (GONÇALVES, 2013).

A reconstrução do conceito e sua concretização no ordenamento jurídico vigente se deu pela criação da Comissão sobre Governança Global em 1992 pela Organização das Nações Unidas que, em 1994, publicou relatório definindo este novo modelo de pensar, problematizar e buscar soluções para os problemas globais como "a totalidade das diversas maneiras pelas quais os indivíduos e instituições, públicas e privadas, administram seus problemas comuns. É um processo contínuo pelo qual é possível acomodar interesses conflitantes e realizar ações cooperativas” (COMISSÃO SOBRE GOVERNANÇA GLOBAL, 1996, P. 2).

O termo em si vai além do simples ato de governar, aproximando-se, efetivamente da noção de governo global. Neste sentido, governança diz respeito à criação e funcionamento de instituições sociais ${ }^{1}$ capazes de solucionar conflitos, facilitando a cooperação ou aliviando problemas de ação coletiva em um mundo constituído por atores interdependentes.

\begin{abstract}
No plano internacional, "governo" abrange o universo dos Estados instituições formais, com soberania nacional, monopólio de poder sobre um determinado território e independência legal de autoridades externas - e o sistema interestatal. Já a "governança" deve ser vista como um processo, que pode ser levado adiante por meio de grupos ou instituições, públicos ou privados, em diversos níveis - subnacional, nacional, regional, internacional, supranacional, etc (MATIAS, 2014, P. 80-81).
\end{abstract}

Talvez o maior e mais reconhecido avanço no campo do Direito Internacional tenha sido a ampliação de participação propiciada pelo desenvolvimento da governança global. A inserção de novos atores permite, nas searas que a governança transita no cenário internacional, a ampliação de diálogos e construção de soluções aos mais diversos problemas que afligem a comunidade global. Com o distanciamento de relações intergovernamentais, organizações não governamentais (ONG), movimentos civis, empresas multinacionais e mercados de capital

\footnotetext{
${ }^{1}$ O termo 'instituições sociais' deve ser interpretado no sentido de serem estabelecidas "regras de jogo" que servirão para definir práticas sociais, designar papéis e orientar interações entre os que as desempenham.
} 
globais passam a influenciar positivamente a boa governança (COMISSÃO SOBRE GOVERNANÇA GLOBAL, 1996).

Um elemento intrínseco do conceito de governança global reside na participação de diversos atores subnacionais, nacionais, regionais, internacionais e supranacionais, proporcionando a estruturação informal de uma rede que tem a capacidade de se mover e se expandir nestas esferas para efetivação de suas metas. Este movimento, ordenado e não hermético, tem como consequência a perda irreversível de parcela de poder dos Estados, gerando o que comumente vem sendo definido como uma governança sem governo: um sistema global que não necessita de uma estrutura formal para gozar dos benefícios de um governo (MATIAS, 2014).

Após a publicação do relatório da Comissão sobre Governança Global em 1996, o elemento da participação ampliada evolui de forma tão harmônica à ideia de governança que, em 2002, o Relatório sobre o Desenvolvimento Humano do PNUD - Programa das Nações Unidas para o Desenvolvimento desenvolve o conceito de governança democrática.

\begin{abstract}
Enquanto a ideia de "boa governança" restringia-se mais aos meios para se alcançar o progresso socioeconômico, a governança democrática defendia que as liberdades civis e políticas, bem como a participação, têm valor fundamental. Assim, na essência, governança democrática significa, além de instituições eficientes e ambiente previsível ao desenvolvimento econômico e político para o crescimento e efetivo funcionamento dos serviços públicos, liberdades fundamentais, respeito aos direitos humanos, remoção da discriminação de raça, gênero e grupo étnico, necessidades das futuras gerações quanto a politicas desenvolvidas (GONÇALVES \& ALMEIDA, 2015, p. 95).
\end{abstract}

Importante mencionar que a concepção da pluralidade de atores não é fruto de uma sociedade recente. A ideia de uma sociedade civil global, por exemplo, obedece uma evolução de mais de cinco séculos, sempre atrelada a interesses e objetivos comuns (WAPNER, 1997). Desenvolvendo-se ora paralelamente, ora umbilicalmente, à expansão da noção de Estado, a sociedade civil, desempenhou e desempenha um relevante papel na (re)construção moral da sociedade justamente por conseguir reunir ideologias comuns.

Muito embora os atores que compõem a governança global não possuam influência equivalentes, os atores não estatais formam a categoria mais numerosa e influente quando se discute, por exemplo, a governança ambiental global (MATIAS, 2014)². Estes atores não

\footnotetext{
${ }^{2}$ O termo "governança ambiental global" deve ser entendido como a soma das organizações, instrumentos de políticas, mecanismos de financiamento, regras, procedimentos e normas que regulam os processos de proteção ambiental global (MATIAS, 2014, p. 85-86).
} 
estatais reivindicam agendas, contribuem significativamente com expertise e podem ditar e influenciar comportamentos dos demais atores e da sociedade em geral.

Existe um problema, obviamente, no grau de influência ou decisão atribuído a estes novos atores. Enquanto a sociedade civil ganha espaço nos foros internacionais, organizandose de modo a atender os ideais comuns, o Direito Público Internacional, onde se insere a governança global, lhe concede reconhecimento parcial (ALCINDO, 2013). Isto se deve, em grande parte, à errônea noção de que a sociedade civil organizada é uma grande "panaceia". O que dizer então quando a visão de mundo da sociedade civil organizada não se coaduna com a visão estatal?

Nesta perspectiva, a questão da legitimidade ${ }^{3}$ destes novos atores pode ser questionada, seja pela sua captura por razões econômicas ou interesses particulares, pelo ativismo exacerbado empregado em suas ações, pela ausência de elementos democráticos que qualifiquem seus representantes ou em última análise a ausência de transparência e accountability em suas ações. Isto porque o que une estes atores nem sempre é a defesa dos direitos humanos ou assuntos de paz. A "liberdade" de agendas se dá justamente por estarem livres da ideia de soberania (ROSENAU, 2000).

\section{GOVERNANÇA GLOBAL NA PROTEÇÃO DOS DIREITOS HUMANOS E DO DIREITO INTERNACIONAL DOS REFUGIADOS}

O Direito Internacional de Proteção da Pessoa Humana integra o ramo de estudo do Direito Internacional Público e surge em resposta às preocupações da sociedade internacional (JUBILUT, 2007), assolada pelos horrores da Segunda Guerra Mundial. Possui três vertentes específicas de proteção: o Direito Internacional dos Direitos Humanos (DIDH), o Direito Internacional Humanitário (DIH) e o Direito Internacional dos Refugiados (DIR) (RAMOS, 2013).

São ramos distintos e autônomos do DIP, mas possuem a mesma história, fundamentos e princípios clássicos (TRINDADE, et all, 1996) e convergem em um grande objetivo: a proteção integral dos direitos da pessoa humana, destinatária final das normas processuais e substantivas de cada um destes ramos (TRINDADE, et all, 1996), como consagra a Conferência de Viena de $1993^{4}$.

\footnotetext{
${ }^{3}$ Entenda-se por legitimidade a concordância e validade de propostas e ações na influência de resultados comuns.

${ }^{4}$ Sobre a integração das vertentes de proteção à pessoa humana proposta na Convenção de Viena de 1993, Flávia Piovesan destaca que: "A Conferência de Viena de 1993 insiste nos meios de se lograr maior coordenação,
} 
O pensamento mais moderno revela, assim, ser ultrapassada a análise dos respectivos ramos do direito de forma compartimentalizada, diante da identidade de propósito na busca da proteção da pessoa humana em toda e qualquer circunstância (TRINDADE, 2006).

A inter-relação dos eixos de proteção mencionados pode ser observada na medida em que compete ao DIDH a proteção do ser humano em todos os aspectos, especialmente na garantia de direitos civis e políticos e direitos econômicos, sociais e culturais; ao DIH compete a proteção do ser humano dos conflitos armados no âmbito internacional ou não internacional; e o DIR atua na proteção do refugiado, desde o momento em que abandona seu país de origem ou residência, no deslocamento de um estado a outro, até o reconhecimento do status de refugiado no país de acolhimento e, eventualmente, cessação desta condição (RAMOS, 2013).

Assim, o Direito Internacional de Proteção da Pessoa Humana se fundamenta no valor da dignidade da pessoa humana, sendo que a aproximação do DIR ao DIDH, objeto de análise deste trabalho, se dá quando o Direito Internacional dos Refugiados sustenta-se no Direito Internacional dos Direitos Humanos, uma vez que sua finalidade é proteger os indivíduos que por motivos de raça, nacionalidade, opinião política, religião ou pertencimento a determinado grupo social, foram forçados a abandonar seu país de origem ou residência para viver em outro Estado $^{5}$.

Enquanto a aplicabilidade do DIR apresenta condições específicas e definidas em instrumentos normativos, o objetivo do DIDH é ampliado, consistindo em zelar e garantir condições mínimas e adequadas para proteger o ser humano de quaisquer violações de direitos pelo Estados ou seus agentes, em âmbito interno ou internacionalmente, ou mesmo por seus pares.

As pessoas que vivem em condição de refúgio tiveram seus direitos humanos ameaçados de violação ou violados (PIOVESAN, 2001), o que permite a estreita relação entre os dois ramos do Direito Internacional. A proteção de ambos os regimes tem, nesta perspectiva, caráter de complementaridade e não de mútua exclusão. Na compreensão de Liliana Lyra Jubilut:

Tal fato é extremamente positivo, pois fortalece a proteção ao refugiado, uma vez que ao mesmo tempo em que se assegura o refúgio, livrando-o de violações de direitos relativos ao seu status civil, ele traz em si a necessidade

sistematização e eficácia dos múltiplos mecanismos de proteção dos direitos humanos existentes. Exige assim o fim de uma visão compartimentalizada e aponta para a necessidade de incorporar a dimensão dos direitos humanos em todas as atividades e programas dos organismos que compõem o sistema das Nações Unidas, somada à ênfase no fortalecimento da interrelação entre direitos humanos, democracia e desenvolvimento". (PIOVESAN, 2001, p. 29).

${ }^{5}$ Artigo $1, \S 1^{\circ}$, (c) da Convenção Relativa ao Estatuto dos Refugiados de 1951. 
de resguardar também os demais direitos humanos, para, com isso, aumentar o nível de proteção dado à pessoa humana $(2007$, p. 61).

Flavia Piovesan (2001) identifica, ainda, quatro pontos de complementação da proteção dada à pessoa humana pelo DIR e pelo DIDH, desde o momento anterior à concessão de refúgio, quando há necessidade de proteção do indivíduo em seu país de origem, contra a não discriminação; a proteção deve se estender para o momento em que a perseguição começa e a liberdade de locomoção e de buscar refúgio devem ser garantidas, além da proteção à vida e integridade física; ao chegar ao país de destino a proteção se verifica por meio do reconhecimento do status de refugiado, e pelo respeito aos direitos fundamentais do refugiado ou asilado; por fim, a necessidade do respeito aos direitos humanos no país de origem, após a cessação das causas que fundamentaram a perseguição.

A observância deste fluxo de proteção, ensejado pelo fluxo paralelo de violações, se mostra fundamental quando se deseja analisar o papel da governança na garantia dos Direitos Humanos. Desde a Segunda Guerra Mundial a forma com que o Estado trata seus indivíduos deixou de ser uma questão exclusiva deste para se tornar uma preocupação, legítima e necessária, de direito e política internacional (PIOVENSAN, 2014). O modelo de soberania westfaliano ${ }^{6}$ passa a ser constantemente provocado pelo surgimento do Direito Internacional dos Direitos Humanos e pela emergência da globalização (PIERIK, 2003).

A consequência de se abandonar o conceito westfaliano de soberania implicou em uma revisão de seus moldes para dar destaque à interdependência dos Estados, continuando, assim, a ideia revisional de soberania nascida antes de 1914 e da Primeira Guerra Mundial. O resultado disto foi a criação da Liga das Nações (1919), com a organização da vida internacional dos Estados, mediante lógica liberal e legalista.

Desse período em diante a soberania passou a ser uma "afirmação do direito internacional positivo, no mais alto nível de seus textos convencionais” (REZEK, 2014, p. 266), destacando-se, entre outros, a própria Carta da Organização das Nações Unidas $(\mathrm{ONU})^{7}$ de 1945, que estabelece em seu art. $2, \S 1^{\circ}$ que a organização “é baseada no princípio da igualdade soberana de todos os seus membros".

Convém destacar que as organizações internacionais, conforme sua teoria jurídica, são entes dotados de personalidade jurídica, formados por Estados que, voluntariamente e no uso

\footnotetext{
${ }^{6}$ Cohan define bem o conceito de soberania westfaliano como sendo a noção de direito absoluto do soberano de excluir atores externos da autoridade doméstica (tradução livre) / "...notion of the absolute right of the sovereign to exclude external actors from domestic authority" (COHAN, 2009-2010)

${ }^{7}$ A Carta da ONU foi assinada por cinquenta países em 25 de abril a 26 de junho de 1945, na Conferência sobre Organização Internacional em São Francisco nos Estados Unidos.
} 
de sua soberania, celebram tratados constitutivos que traçam seus âmbitos material e territorial de atuação (REZEK, 2014). Os motivos pelos quais os Estados decidem se associar revelam uma crise na solução de problemas de forma individualizada que somente através da união de esforços pode ser solucionada (CASELLA, 2009).

Apesar de terem personalidade jurídica e vontade distinta dos Estados que as formam, as organizações internacionais raramente são vistas como funcionalmente independentes dos respectivos Estados. Há uma relação indissociável entre os membros e a associação, a qual ocorre não apenas no sentido jurídico, mas principalmente na dimensão política de sua atuação (REZEK, 2014).

A Carta da ONU, neste sentido, ao estabelecer a igualdade dos Estados como nações soberanas sob a lei internacional, reconhece a igualdade e dignidade dos Estados e povos, protege suas identidades originais e sua liberdade nacional, além de afirmar seu direito de moldar e determinar o próprio destino. Atualmente, se concebe um modelo de soberania com responsabilidade, que se propõe a conciliar a soberania estatal com o dever dos Estados de proporcionar e manter padrões mínimos de dignidade e serviços básicos à sua população.

No mundo atual, no entanto, as organizações internacionais existentes já não são capazes de lidar ou solucionar conflitos utilizando a mesma abordagem utópica que pautou suas criações. A capacidade destas instituições promoverem coesão social encontra dois obstáculos: (i) seu âmbito material limitado - o âmbito de eficiência de suas atividades é restrito; (ii) seu distanciamento dos cidadãos que, a princípio, participam apenas como representados pelo Estado - não existem instrumento de legitimação democrática destes (CALDUCH, 1991).

Qual seria então o modelo adequado para lidar com violações de direitos humanos? Ainda que a abordagem empregada pelas organizações internacionais e organizações não governamentais (ONG’s) seja passível de críticas $^{8}$, afrouxar a soberania estatal para permitir que outros atores sejam integrados na solução de problemas comuns é tão ou mais complicado do que criar um modelo eficaz de monitoramento, promoção e proteção de direitos humanos apto a reverter a crise de direitos vivida na atualidade.

Cabe lembrar que a própria Declaração Universal de Direitos Humanos (DUDH) de 1948 atribui a todo indivíduo a responsabilidade pela promoção dos direitos humanos. Assim prevê o artigo XXIX da DUDH: "toda pessoa tem deveres para com a comunidade, na qual o livre e pleno desenvolvimento de sua personalidade é possível". Permitir e encorajar a

\footnotetext{
${ }^{8}$ Transparência nas ações, legitimidade das ONGs, forma da eleição dos membros são apenas algumas das críticas normalmente suscitadas.
} 
participação da sociedade civil global atende, assim, aos princípios morais e éticos da DUDH, atitude que deveria ser encorajada pelos Estados (PIOVESAN, 2014).

Dentre os modelos de proteção de direitos humanos existentes atualmente, encontramos no âmbito das Nações Unidas o sistema global, tanto de caráter geral como de caráter específico. Dentro da proteção específica nos interessa a proposta pela Convenção de Genebra Relativa ao status de Refugiados de 1951, primeira convenção internacional a proteger especificamente estes indivíduos e a trata-los de forma individual e contextualizada?

De forma pioneira em termos de governança global, referida Convenção prevê em seus considerandos que, em razão do fato do direito de asilo "resultar encargos indevidamente pesados para certos países e que a solução satisfatória dos problemas cujo alcance e natureza internacionais a Organização da Nações Unidas reconheceu, não pode, portanto, ser obtida sem cooperação internacional” (Nações Unidas, 1951).

Ainda que o instituto da governança global ainda não estive consolidado no âmbito do Direito Internacional Público resta clara a necessidade da cooperação internacional através de múltiplos atores - verdadeira pedra de toque da governança - para a solução das questões que envolvem o refúgio, em todas as fases do fluxo dos refugiados: prevenção no país de origem; integração no país de destino na impossibilidade de retorno ao país de origem; realocação realizada pelo assentamento em outro Estado e no repatriamento.

A direção e coordenação da ação internacional para proteger e ajudar refugiados em todo o mundo e encontrar soluções duradouras para elas compete ao Alto Comissariado das Nações Unidas para Refugiados (ACNUR - UNHCR na sigla em inglês - United Nations High Commissioner for Refugees), que iniciou seus trabalhos em 1950, antes mesmo da promulgação da Convenção de $51^{10}$.

O ACNUR baseia suas ações na Convenção de 1951 e no seu Protocolo de 1967, documentos que constituem o quadro normativo essencial de suas atividades. Tem como principal missão assegurar os direitos e o bem-estar dos refugiados, englobando a garantia de qualquer pessoa exercer o direito de buscar e gozar de refúgio seguro em outro país e, caso assim deseje, regressar ao seu país de origem. Busca soluções duradouras, seja por meio da

\footnotetext{
${ }^{9}$ A Convenção de 51 consagra o período (1938-1951) de qualificação individual, com a consideração de critérios pessoais, na determinação do status de refugiado. Até então, no período que vigorou de 1921 a 1938 , o critério determinante para se reconhecer uma pessoa como refugiada era o seu pertencimento a certo coletivo, não se considerando suas condições pessoais (ANDRADE, 1996).

${ }^{10}$ As informações sobre o ACNUR foram consultadas no site oficial do órgão no Brasil, estando as informações disponíveis em http://www.acnur.org/t3/portugues/informacao-geral/a-missao-do-acnur/, acesso em 10 de abril de 2016.
} 
integração ao país de destino, seja por meio do reassentamento em um terceiro país, seja por meio do regresso ao país de origem, se for esta a vontade do refugiado e se mostrar viável.

O ACNUR atua de maneira imparcial e sem distinção quanto à condição da pessoa, com atenção especial às crianças e mulheres. Faz cumprir os propósitos da Carta das Nações Unidas no que tange à manutenção da paz e segurança internacionais; desenvolvimento de relações amistosas entre as nações; e encorajamento do respeito pelos direitos humanos e pelas liberdades fundamentais. Age em estreita colaboração junto a governos, organizações regionais e internacionais e organizações não-governamentais.

No caso específico da proteção ao refugiado, não é exagero dizer que a arquitetura do sistema se beneficia da participação ampliada. Pressupõe-se que em se tratando de um dos eixos de proteção de direitos humanos, tal participação é sempre bem vinda. No entanto, neste mister, verifica-se uma dicotomia.

Por um lado, a participação da sociedade civil no campo dos direitos humanos em geral apresenta inúmeros obstáculos, na medida em que o agente violador dos Direitos Humanos sempre será o Estado. Ampliar a participação de atores interdependentes da sociedade civil global implica, nestes casos, na assunção do risco de estar continuamente no banco dos réus no cenário jurisdicional internacional. Estado soberano algum transita com facilidade neste terreno. Por outro lado, em diversos momentos os demais atores muitas vezes agem assumindo funções do Estado, como é corriqueiro na proteção e acolhimento aos refugiados (HAYDU, 2011). Ou seja, há uma multiplicidade de atores dedicados ao diagnóstico, construção, implementação e monitoramento de um sistema de governança.

\section{PROTEÇÃO AOS REFUGIADOS NO BRASIL: A INTEGRAÇÃO LOCAL E O PAPEL DAS CÁTEDRAS SÉRGIO VIEIRA DE MELLO}

O Brasil é signatário da Convenção de Genebra sobre o Status de Refugiados de 1951 e do seu Protocolo Adicional de 1967, além da Declaração de Cartagena de 1984, e integra o Comitê Executivo do ACNUR desde 1958. No âmbito doméstico, o Brasil promulgou o Estatuto do Refugiado (Lei 9.474/97) que define as normas aplicáveis aos refugiados e solicitantes de refúgio, ampliando o conceito de refugiado para além do temor de perseguição, incluindo a generalizada violação de direitos humanos. A legislação brasileira respeita, assim, o espírito de Cartagena, alusão feita à Declaração de Cartagena de $1984^{11}$.

\footnotetext{
${ }^{11}$ A Declaração de Cartagena estabelece um marco no âmbito regional para tratar do problema dos refugiados, uma vez que apresenta um conceito ampliado de refugiado. A cada 10 anos sua elaboração é celebrada resultando
} 
A Lei 9747, de 1997, dispõe que será reconhecido como refugiado o indivíduo que:

I - devido a fundados temores de perseguição por motivos de raça, religião, nacionalidade, grupo social ou opiniões políticas, encontre-se fora de seu país de nacionalidade e não possa ou não queira acolher-se à proteção de tal país; (...)

III - devido à grave e generalizada violação de direito humanos, é obrigado a deixar seu país de nacionalidade para buscar refúgio em outro país (BRASIL, 1997).

A legislação brasileira de refugiados também criou o Comitê Nacional para Refugiados (CONARE) órgão responsável por analisar os pedidos e declarar o reconhecimento, em primeira instância, da condição de refugiado, bem como por orientar e coordenar as ações necessárias à eficácia da proteção, assistência e apoio jurídico aos refugiados no Brasil. O número de refugiados atualmente cadastrados no Brasil é de 8,4 mil ${ }^{12}$. Além desse número de refugiados, observa-se uma tendência de aumento nos fluxos migratórios em direção ao Brasil, como mais recentemente de haitianos.

A criação do CONARE consolida a estrutura tripartite na atenção aos refugiados: instituições domésticas (representadas pela Cáritas Arquidiocesana), organização internacional (ACNUR) e governo brasileiro (representado por seus órgãos e presidindo o CONARE) (Leão, 2003). Prevista na lei 9747/97, esta estrutura trabalha para alcançar soluções duráveis para os refugiados, quais sejam a repatriação, o reassentamento e a integração local. Para este trabalho, nos interessa especialmente a integração local.

A integração local ocorre quando o refugiado é acolhido pelo país de ingresso (HAYDU, 2011). Esta solução é positiva por ser imediata, não no sentido de ser rápida, mas no sentido de não haver necessidade de aguardar as circunstâncias do país de origem se tornarem favoráveis ao retorno ou reassentamento em um terceiro país. Não obstante, a integração local apresenta algumas barreiras como a diferença cultural e a falta de receptividade da comunidade local.

Em razão disto, o ACNUR define algumas ações a serem realizadas pelos Estados com vistas a garantir a integração dos refugiados: i) apoiar os esforços para facilitar a integração local; ii) aceitação da comunidade local, para evitar animosidades; iii) a integração local tem que ser economicamente viável, contando inclusive com financiamento externo que lhe

em outros documentos protetivos, como a Declaração de São José sobre Refugiados e Pessoas Deslocadas de 1994 (Declaração de São José), o Plano de Ação do México para Fortalecer a Proteção Internacional dos Refugiados na América Latina de 2004 (Plano de Ação do México) e o mais recente de 2014, a Declaração e Plano de Ação do Brasil no marco de 30 anos da Declaração de Cartagena.

${ }^{12}$ CONARE, Refúgio no Brasil - Estatística. 
proporcione êxito; iv) deve ser voluntária; v) integração plena dos refugiados, inclusive com a possibilidade de adquirir a cidadania do país (HAYDU, 2011).

A integração local é realizada na cooperação tripartite acima mencionada, mas tem a sociedade civil assumido papel de destaque, desempenhando importante papel nas ações de proteção, assistência e integração dos refugiados no Brasil. A Cáritas Arquidiocesana, vinculada à Igreja Católica, assume o papel de representante da sociedade civil organizada frente ao CONARE, atuando principalmente em São Paulo, no Rio de Janeiro e no Paraná, por serem os estados de maior concentração de refugiados no país (ACNUR, 2016).

A atuação da sociedade civil se mostra ampliada no Brasil ${ }^{13}$, contando com mais de 100 organizações não governamentais atuando na integração local dos refugiados, sendo a maior rede de suporte na América Latina (HAYDU, 2011). O Brasil tem também ampliado as políticas de integração, por exemplo, favorecendo o acesso dos refugiados à documentação, e, de forma mais tímida, ao Programa Bolsa Família. Verifica-se também a criação de Comitês Estaduais para Refugiados nos estados do Rio de Janeiro ${ }^{14}$, São Paulo ${ }^{15}$, Paraná $^{16}$ e Mato Grosso do Sul $^{17}$. A importância da participação da sociedade civil na construção de políticas para refugiados mostrou-se clara na pesquisa "Migrantes, apátridas e refugiados: subsídios para o aperfeiçoamento de acesso a serviços, direitos e políticas públicas no Brasil”, desenvolvida pelo Ministério da Justiça e pelo IPEA (JUBILUT, 2015).

Uma ação muito importante e que amplia ainda mais a cooperação e o compartilhamento de responsabilidades e comprometimento da sociedade civil se deu em 2003, por meio da criação das Cátedras Sérgio Vieira de Mello (CSVM). Proposta pelo Escritório Regional do ACNUR para a América do Sul, a CSVM faz homenagem em seu título ao funcionário de carreira das Nações Unidades por 33 anos e que por 27 anos dedicou-se ao ACNUR, morto em atentado ao Escritório da ONU em Bagdá em 19/08/2003. Tem como

\footnotetext{
13 "Para garantir a assistência humanitária e a integração dos refugiados no Brasil, o ACNUR implementa projetos com organizações da sociedade civil em diferentes cidades do país, como a Associação Antônio Vieira (ASAV), a Cáritas Arquidiocesana do Paraná (CAPR), a Cáritas Arquidiocesana do Rio de Janeiro (CARJ), a Cáritas Arquidiocesana de São Paulo (CASP), a Eu Conheço Meus Direitos (IKMR) e o Instituto Migrações e Direitos Humanos (IMDH). Também conta com parcerias no setor privado e no mundo acadêmico para ampliar o apoio às populações sobre seu mandato. " (ACNUR, 2016, p. 17).

14 Disponível em: <http://www.acnur.org/t3/portugues/noticias/noticia/rio-instala-comite-estadual-pararefugiados/>. Acesso em 10 de abril de 2016.

${ }^{15}$ Disponível

<http://perfil.sp.gov.br/site/exibe.asp?entidadecodigoid=8820\&tt=COMIT\%CA\%20ESTADUAL\% 20PARA\%20OS\%20REFUGIADOS\%20-\%20CER>. Acesso em 10 de abril de 2016.

${ }^{16}$ Disponível em: <http://www.aen.pr.gov.br/modules/noticias/article.php?storyid=69956>. Acesso em 10 de abril de 2016.

17 Disponível em: <http://www.sedhast.ms.gov.br/criacao-do-comite-estadual-do-migrante-e-refugiado-eproposto-em-audiencia-publica/>. Acesso em 10 de abril de 2016.
} 
objetivo a promoção do ensino nas Universidades latino-americanas e da difusão do Direito Internacional dos Direitos Humanos, Direito Internacional Humanitário, Direito Internacional dos Migrantes, Direito Internacional dos Refugiados (RODRIGUES, 2007).

Na perspectiva do Brasil, o Termo de Referência - Cátedra Sérgio Vieira de Mello, define como objetivo geral "promover e difundir o direito internacional dos refugiados que se encontrem sob a proteção internacional do Governo do Brasil" (ACNUR, 2012, p. 1) ${ }^{18}$ e como objetivos específicos capacitar e formar professores e estudantes universitários, com vistas a sensibilizar e estimular a produção de conhecimento científico, com foco na formação de futuros agentes de transformação. Visa ainda a integração dos refugiados às universidades.

Os primeiros convênios para instituição da CSVM foram assinados em outubro de 2003 entre o ACNUR e a PUC-RJ no Rio de Janeiro e na UNICEUB, em Brasília (RODRIGUES, 2014). Em 2004, adequando os propósitos da CSVM ao Plano de Ação do México - PAM (ACNUR, 2004), passa a ser prioridade nas ações das Cátedras o "trabalho direto com os refugiados" (ACNUR, p. 2), mas ainda sendo estimulado o desenvolvimento acadêmico.

O PAM foi firmado durante a reunião comemorativa do vigésimo aniversário da Declaração de Cartagena, realizada na cidade do México. O grande objetivo deste plano foi combater os problemas enfrentados pelos deslocados internos e refugiados na América Latina. Especificamente, o PAM busca melhorar a proteção e assistência humanitária na região e responder, noutro turno, aos grandes fluxos de refugiados. Divide-se, assim, em dois grandes eixos: de proteção e de soluções duráveis.

Neste sentido, os convênios entre Universidades e o ACNUR para a instituição das Cátedras foram ampliados a partir de 2004, provavelmente em razão das adequações ao Plano de Ação do México. Na sequência, no entanto, as atividades das Cátedras começaram a estagnar, o que levou o ACNUR a relançar as Cátedras em 2010, no I Seminário Nacional Cátedra Sérgio Vieira de Mello, ocorrido na Universidade Católica de Santos - UniSantos - Santos/SP. A UniSantos havia firmado convênio com o ACNUR em 2007, sendo a Cátedra vinculada ao Programa de Pós-Graduação Stricto Sensu em Direito (RODRIGUES, 2014).

A escolha da Universidade Católica de Santos para sediar o I Seminário se deu em razão ao grande comprometimento de sua Cátedra, em desenvolver as ações propostas pelo convênio: criou a disciplina Direito Internacional dos Refugiados no programa de pósgraduação; debatia o tema na graduação; estimulava a produção científica sobre o tema, além

${ }^{18}$ As informações acerca das ações específicas das Cátedras no Brasil foram acessadas no Termo de Referência - Cátedra Sérgio Vieira de Mello, (ACNUR, 2012). 
de estar localizada em território simbólico de fronteira úmida, O Porto de Santos (RODRIGUES, 2014). Desde então foram realizados seis Seminários Nacionais: 2010, UniSantos - Santos/SP; 2011, UVV - Vila Velha/ES; 2012, PUC/SP - São Paulo/SP; 2013, UFPR - Curitiba/PR; 2014, UFRGS - Porto Alegre/RS (RODRIGUES, 2014); 2015, UFMS - Dourados/MS.

A grande importância da CSVM é colaborar para que a proteção dos Direitos dos Refugiados e dos Direitos Humanos seja trazida para a academia. Seja na perspectiva do ensino, da pesquisa ou da extensão, as ações da Cátedra visam produzir conhecimento e integrar o refugiado na sociedade que o acolheu. A produção de conhecimento científico sobre o tema se mostra fundamental. Mas, talvez o grande mérito da Cátedra seja a divulgação do tema para a comunidade em geral, para desconstruir mitos acerca do refúgio e do refugiado e com isso garantir maior acolhimento e inserção dos refugiados.

Vivemos um momento que o grande desafio da proteção dos direitos humanos transcende o seu mero reconhecimento, sendo fundamental a sua implementação (BOBBIO, 1992), com a inclusão dos refugiados. Para isso, algumas das Universidades incluíram em seu plano de ação vinculado à Cátedra, a oferta de vagas para refugiados. Por meio de vestibulares especiais, algumas universidades como a Universidade Federal de São Carlos (UFSCAR/SP), a Universidade Federal de Minas Gerais (UFMG/MG) e a Universidade Católica de Santos (UniSantos/SP) (RODRIGUES, 2014), contam em seu corpo discente com refugiados, proporcionando o acesso dos mesmos ao ensino formal, passo fundamental para a inclusão no mercado de trabalho. Educação e trabalho são condições fundamentais para que a integração dos refugiados se dê de maneira plena e respeitosa aos Direitos Humanos.

As Cátedras não contam com apoio financeiro do ACNUR, sendo responsáveis por otimizar suas estruturas e recursos humanos para as finalidades da CSVM, mostrando, assim, um real envolvimento da sociedade civil no compromisso com a consecução da política pública. Segundo Rodrigues (2014), o desenvolvimento da CSVM no Brasil "com abrangência e incidência sociais muito maiores que sua proposta original transformou a CSVM em uma prática inovadora na relação entre uma agência da ONU e universidades do país” (p. 27). Segundo o mesmo autor, as ações da Cátedra Sérgio Vieira de Mello envolvendo ensino, pesquisa e extensão "incluindo e apoiando a integração de refugiados, se conecta com a política internacional e regional para os refugiados, e as políticas públicas de direitos humanos da esfera pública, apoiando o exercício do direito à educação, ao trabalho, à renda, à habitação, entre outros" (RODRIGUES, 2014, p. 27). 
A Cátedra Sérgio Vieira de Mello revela-se, assim, como profícuo exemplo de como a governança global consolidada na responsabilidade compartilhada e a participação ampliada podem contribuir na integração local dos refugiados, quando se propõem a estender os espaços de debate para além da gestão pública, proporcionando a participação da sociedade, produzindo conhecimento, divulgando informação e incluindo os refugiados em espaços de socialização fundamentais para sua integração local.

\section{CONCLUSÃO}

São muitos os desafios globais contemporâneos. Definir o papel que os atores inseridos na governança global terão na condução de processos e na busca de soluções a problemas comuns não é tarefa simples considerando a multiplicidade de violações de direitos humanos observadas na atualidade.

As dificuldades enfrentadas na proteção dos direitos humanos e no direito dos refugiados para efetiva consolidação em uma sociedade global e plural, podem ser minimizadas através do papel desempenhado pela governança global. Ao passo que não se discute tratar-se de um sistema complexo onde o consenso é dificilmente atingido, a consolidação da responsabilidade compartilhada, pela necessária inserção da sociedade civil junto ao poder público e órgãos internacionais efetiva a premissa trazida há mais de 50 anos pela Convenção de 51 .

Em um momento de crise humanitária histórica, esta estrutura tripartite fortalecida, pode ser vetor de promoção e proteção de Direitos Humanos, a despeito de quaisquer diferenças culturais, econômicas e sociais, atingindo, finalmente, um denominador comum: da maior proteção da pessoa humana.

A atuação das Cátedras Sérgio Vieira de Mello revela-se um elo fundamental nesta cadeia de promoção, proteção e integração dos refugiados. Mas ainda há muito o que conquistar.

Ampliar a participação da sociedade civil ao mesmo tempo que aproxima o indivíduo das lutas coletivas, pode gerar uma desconfiança do poder público no sentido de ampliar sua zona de vulnerabilidade diante do maior controle exercido por esta multiplicidade de atores, desnudando tantas outras violações de direitos perpetradas pelo Estado. Justamente em razão disso, não é possível recuar. É fundamental fortalecer a participação social e a academia pode ser importante sustentáculo quando se propõe a produzir saber e divulgar o conhecimento sobre 
as temáticas, além de possibilitar espaços de integração dos refugiados pelo viés da educação, tão importante para sua integração econômica.

\section{REFERENCIAS}

ACNUR. Plano de Ação do México, 2004. Disponível em: $<$ http://www.acnur.org/t3/fileadmin/Documentos/portugues/BD_Legal/Instrumentos_Internac ionais/Declaracao_e_Plano_de_Acao_do_Mexico.pdf?view=1>. Acesso em $10 \mathrm{de}$ abril de 2016.

ACNUR. Termo de Referência - Cátedra Sérgio Vieira de Mello, 2012. Disponível em: <http://www.acnur.org/t3/fileadmin/scripts/doc.php?file=t3/fileadmin/Documentos/portugues/ eventos/TERMO_DE_REFERENCIA_CSVM_2012>. Acesso em 10 de abril de 2016.

BOBBIO, Norberto. A Era dos Direitos. Rio de Janeiro: Campus, 1992.

BRASIL. Congresso Nacional. Lei 9747, de 22 de julho de 1997 - Define mecanismos para a implementação do Estatuto dos Refugiados de 1951, e determina outras providências. Diário Oficial da União em 23 de julho de 1997.

CASELlA, P. B.; ACIOLY, H; SILVA, G. E do N. Manual de Direito Internacional Público. $17^{\mathrm{a}}$ ed. São Paulo: Saraiva, 2009.

CALDUCH, R. Relaciones Internacionales. Edit. Ediciones Ciencias Sociales. Madrid,1991.

COMISSÃO SOBRE GOVERNANÇA GLOBAL. Nossa Comunidade Global. Relatório da Comissão sobre Governança Global. Rio de Janeiro: Ed. FGV, 1996.

GONÇALVES, A. Governança Global e o Direito Internacional Público. Direito Internacional Atual. Ed. Campus Jurídico. 2013.

GONÇALVES, A.; COSTA, J. A. F. Governança Ambiental Global: possibilidades e limites. Direito Ambiental Internacional: avanços e retrocessos. Ed. Atlas, 2015.

HAYDU, M. A Integração de Refugiados no Brasil. In: CARVALHO RAMOS, A.; RODRIGUES, G.; ALMEIDA, G. A. (orgs.). 60 anos de ACNUR: perspectivas de future. 2011.

JUBILUT, L. L. O Direito Internacional dos Refugiados e sua aplicação no ordenamento jurídico brasileiro. São Paulo: Método, 2007.

JUBILUT, L. L. Migrantes, apátridas e refugiados: subsídios para o aperfeiçoamento de acesso a serviços, direitos e políticas públicas no Brasil. Brasília: Ministério da Justiça, Secretaria de Assuntos Legislativos; IPEA, 2015.

LEÃO, R. Z. R. A temática do refúgio no Brasil após a criação do Comitê Nacional para os Refugiados - CONARE. In: MILESI, Rosita (Org.). Refugiados: realidade e perspectivas. Brasília: CSEM/IMDH; Loyola, 2003. 
MATIAS, E. F. P. A humanidade contra as cordas: a luta da sociedade global pela sustentabilidade. Ed. Paz \& Terra, 2014.

NAÇÕES UNIDAS. Convenção de Genebra sobre o Status de Refugiado. Genebra: ONU, 1951.

PIERIK, R. Globalization and Global Governance: a conceptual analysis. 2003. Hague Joint Conference.

PIOVESAN, Flávia. O Direito de Asilo e a Proteção Internacional dos Refugiados. In: ARAUJO, Nadia de e ALMEIDA, Guilherme A. de (coords). O Direito Internacional dos Refugiados: uma perspectiva brasileira. Rio de Janeiro: Renovar, 2001.

PIOVESAN, F. Temas de Direitos Humanos. $7^{\mathrm{a}}$ ed. São Paulo: Saraiva, 2014.

REZEK, J. F. Direito Internacional público: curso elementar. $15^{\text {a }}$ ed. rev. e atual. São Paulo: Saraiva, 2014.

RODRIGUES, G. M. A. Direito Internacional dos Refugiados. Uma perspectiva brasileira. In: Anuário Brasileiro de Direito Internacional, (II). v.I, p. 164-178, 2007.

RODRIGUES, G. M. A. ACNUR e Universidades: a Cátedra Sérgio Vieira de Mello (CSVM) no Brasil. In Cadernos de Debates Refúgio, Migrações e Cidadania, v. 9, n. 9. Brasília: Instituto Migrações e Direitos Humanos, 2014, p. 13-30.

RAMOS, A. de C. Teoria geral dos direitos humanos na ordem internacional. $3^{\mathrm{a}}$ ed. São Paulo: Saraiva, 2013.

ROSENAU, J. N. Governança, Ordem e Transformação na Política Mundial. In: ROSENAU, J. N.; CZEMPIEL, Ernst-Otto. Governança sem governo: ordem e transformação na política mundial. Brasilia: Ed. Unb e São Paulo: Imprensa Oficial do Estado, 2000.

TRINDADE, A. A. C. A Humanização do Direito Internacional. Belo Horizonte: Del Rey, 2006.

TRINDADE, A. A. C.; PEYTRIGNET, G.; RUIZ DE SANTIAGO, J.; INSTITUTO INTERAMERICANO DE DIREITOS HUMANOS; COMITÊ INTERNACIONAL DA CRUZ VERMELHA; ALTO COMISSARIADO DAS NAÇÕES UNIDAS PARA REFUGIADOS. As Três Vertentes da Proteção Internacional dos Direitos da Pessoa Humana: Direitos Humanos, Direito Humanitário e Direito dos Refugiados. San José; Brasília: ACNUR: CICV: IIDH, 1996. p. 30.

WAPNER, P. Governance in Global Civil Society. In: Young, Oran R. (ed). Global Governance. Drawing Insights from Environmental Experience. Cambridge/London: The MIT Press, 1997. 